\title{
Comparison of alfaxalone-medetomidine and tiletamine-zolazepam in rescued common palm civets (Paradoxurus musangus)
}

\author{
Ali Anwar AHMAD ${ }^{1) *}$, Norsham Abd WAHAB ${ }^{1)}$, Clara Wenjing YEO ${ }^{1)}$, \\ Serena Jocelyn Wai Yin $\mathrm{OH}^{1)}$ and Hui Cheng $\mathrm{CHEN}^{2)}$ \\ ${ }^{1)}$ Department of Conservation, Research and Veterinary Services, Wildlife Reserves Singapore, 729826 \\ Singapore \\ ${ }^{2)}$ Department of Companion Animal Medicine \& Surgery, Faculty of Veterinary Medicine, Universiti Putra \\ Malaysia, Serdang 43400, Malaysia
}

J. Vet. Med. Sci.

81(1): 48-52, 2019

doi: 10.1292/jvms.18-0297

Received: 3 June 2018

Accepted: 2 November 2018

Published online in J-STAGE:

15 November 2018

\begin{abstract}
Forty rescued common palm civets were anesthetized. Twenty animals received intramuscular injections of alfaxalone $5 \mathrm{mg} / \mathrm{kg}$ and medetomidine $0.05 \mathrm{mg} / \mathrm{kg}$ (A-M group), whereas twenty animals received $5 \mathrm{mg} / \mathrm{kg}$ of tiletamine and zolazepam (T-Z group). The A-M group was reversed with atipamazole $0.25 \mathrm{mg} / \mathrm{kg}$. There were no significant differences in the time from anesthetic injection to induction and intubation between the A-M and T-Z groups. The time from the injection of reversal in the A-M group and the time from cessation of isoflurane in the T-Z group to extubation, first response to recovery and ambulation were longer $(P<0.05)$ in the T-Z group. The T-Z group recorded lower $(P<0.05)$ rectal temperatures compared to the A-M group. This study showed that both drug combinations can be used effectively for the immobilization of civets. The A-M combination provided better anesthetic depth, but with higher incidence of bradycardia and hypoxemia. The recovery time was reduced significantly as atipamezole was used as a reversal agent in the $\mathrm{A}-\mathrm{M}$ combination.

KEY WORDS: alfaxalone-medetomidine, common palm civet, Paradoxurus musangus, tiletaminezolazepam
\end{abstract}

Civets, often commonly referred to as civet cats, are carnivorous mammalians from the family Viverridae. Civets occur across Africa, the Iberian Peninsula and Asia. The common palm civet (Paradoxurus musangus) is a species recorded throughout South and Southeast Asia, including Singapore. The common palm civet is amongst the few species of wildlife that are able to adapt to an urban habitat [19]. Human-animal conflict often is the result of the common palm civet's preference to reside in the roof of houses, foraging of fruiting trees in orchards or gardens, disturbances from noise and excrement [28]. In recent times, civet coffee or 'kopi luwak' attracted a great deal of attention for its supposed taste and value [3]. This led to an increase in the number of animals captured illegally from the wild and kept in poor captive conditions for civet coffee production [2, 3, 23].

Both physical and chemical restraints are commonly used methods of the restraint for wild civet [4]. The drugs and dosages for the chemical restraint of civets are based on those established for other small carnivore species such as kinkajous and raccoons [4]. Ketamine alone, ketamine-medetomidine, ketamine-butorphanol-medetomidine, ketamine-diazepam and tiletamine-zolazepam (T-Z) are commonly used anesthetic drug protocols for civet chemical immobilization. The anesthetic drug combination of T-Z is one of the most commonly used protocol $[4,16]$ for small carnivores such as civets.

Alfaxan $^{\circledR}$-CD RTU (Alfaxan ${ }^{\circledR}$, Rutherford, New South Wales, Australia) is a neuroactive steroid molecule with the properties of a general anesthetic, which is gaining popularity in the anesthesia of domestic dogs and cats. Alfaxan ${ }^{\circledR}$ comprises of alfaxalone and is a newer version of a discontinued anesthetic drug known as Saffan ${ }^{\circledR}$ (Glaxovet, Harefield, U.K.), which is made up of alfaxalone and alphadolone. Alfaxan ${ }^{\circledR}$ is solubilized in 2-hydroxypropyl-beta cylodextrin; a large oligosaccharide and has not been associated with histamine release [17]. Previously, Saffan ${ }^{\circledR}$ was solubilized in Cremohphor EL, which have been reported to be associated with histamine release in cats resulting in hyperemia, edema, partial laryngeal spasm during intubation and post-operative vomiting [5].

The primary mechanism of action of alfaxalone is the modulation of the neuronal cell membrane chloride transport, induced by binding to the type A gamma-aminobutyric acid (GABAA) cell surface receptor, resulting in the hyperpolarization of the cells and inhibition of neuronal impulse propagation [17]. Alfaxalone is rapidly metabolized by the liver and has a relatively short plasma half-life [7, 27]. 
Table 1. Criteria used to evaluate the immobilization quality in rescued common palm civets (Paradoxurus musangus) anaesthetized with alfaxalone-medetomidine (A-M) or tiletamine-zolazepam (T-Z)

\begin{tabular}{ll}
\hline \multicolumn{1}{c}{ Rating } & \multicolumn{1}{c}{ Immobilization quality } \\
\hline Excellent & $\begin{array}{l}\text { Animal remains sufficiently immobilized throughout the health examination with good muscle } \\
\text { relaxation, loss of jaw tone, acceptance of endotracheal tube and had no response to painful } \\
\text { stimuli without supplementary isoflurane. }\end{array}$ \\
\hline Good & $\begin{array}{l}\text { Animal remains sufficiently immobilized with good muscle relaxation, loss of jaw tone, } \\
\text { acceptance of endotracheal tube and had no response to painful stimuli, but required } \\
\text { supplementary isoflurane during the health examination. }\end{array}$ \\
\hline Moderate & $\begin{array}{l}\text { Animal remains sufficiently immobilized with good muscle relaxation, loss of jaw tone, and } \\
\text { no response to painful stimuli, but required supplementary isoflurane to intubate and maintain } \\
\text { immobilization during the health examination. }\end{array}$ \\
\hline Poor & $\begin{array}{l}\text { Animal not immobilized and required supplementary isoflurane to intubate and maintain } \\
\text { immobilization for the health examination. }\end{array}$ \\
\hline
\end{tabular}

Premedication with medetomidine and other narcotic drugs allow for the reduction of the dosage of alfaxalone used in chemical restraint $[7,17,18]$. There are several documented dosages developed for the use of alfaxalone alone, or in combination with other sedative drugs such as medetomidine and azaperone in the chemical restraint and anesthesia of exotic animals and wildlife [1, $14,25]$. However, there is limited information on the usage of these anesthetic drugs, their efficacy and their effects in civets. The objective of this study is to determine the efficacy, cardiorespiratory effect and possible side effects of the alfaxalone-medetomidine (A-M) combination and T-Z combination in the common palm civets.

\section{MATERIALS AND METHODS}

The study was conducted in Wildlife Reserves Singapore (WRS) adhering to the ethical and animal welfare principles and was approved by the Animal Welfare and Ethics Committee of WRS.

Civets that were rescued by non-profit organizations and governmental agencies were sent to the hospital based at the Wildlife Health and Research Centre of the Singapore Zoo for routine pre-release health assessments and biometric measurements. Upon admission, they were quarantined for three to five days before the pre-release health assessments were conducted. The civets were fasted for a minimum of eight hours prior to the health check. They were transferred from quarantine to a squeeze cage to ensure complete intramuscular administration of the drugs.

Before drug administration, the body weights of the civets were determined by weighing the squeeze cage with the animal and subtracting the weight of the squeeze cage, so that an accurate dose of the anesthetic agent was administered. The civets were randomly assigned, either into A-M or T-Z group. The A-M group received $5 \mathrm{mg} / \mathrm{kg}\left(0.5 \mathrm{ml} / \mathrm{kg}\right.$ ) of alfaxalone (Alfaxan $\left.{ }^{\circledR}\right)$ and 0.05 $\mathrm{mg} / \mathrm{kg}(0.05 \mathrm{ml} / \mathrm{kg})$ of medetomidine (Domitor ${ }^{\circledR}$, Orion, Espoo, Finland). The T-Z group received $5 \mathrm{mg} / \mathrm{kg}(0.05 \mathrm{ml} / \mathrm{kg})$ of Zoletil ${ }^{\circledR}$ $\left(50 \mathrm{mg} / \mathrm{m} l\right.$ tiletamine $+50 \mathrm{mg} / \mathrm{m} l$ zolazepam, Zoletil ${ }^{\circledR} 100$, Virbac, Carros, Frances $)$.

Several intervals were defined and recorded during the induction and recovery periods in both groups. The time from anesthetic injection to initial sedation was recorded as the amount of time it took for the head and neck of the civets to be lowered. The time to heavy sedation was recorded as the amount of time it took for the animals to display a total loss of response to stimuli while still retaining jaw tone. The time to light anesthesia was recorded as the amount of time it took the animals to have complete relaxation of their heads, limbs and jaws with no response to handling. The civets were intubated once the plane of light anesthesia was reached. Supplementary isoflurane (Attane, Piramal Healthcare, Bethlehem, PA, U.S.A.) was administered via placement of gas mask if the civets were not sufficiently immobilized or retained jaw tone to enable intubation. Isoflurane was also administered to civets that show signs of recovery during the procedure enable safe handling of the animal. Lignocaine spray $\left(\mathrm{Xylocane}^{\circledR} 10 \%\right.$ Pump Spray, AstraZeneca, Cheshire, U.K.) was applied to the pharynx if laryngeal or pharyngeal reflex was still present during intubation. The first reading for heart rate (HR), respiratory rate (RR), rectal temperature (RT) and non-invasive hemoglobinoxygen saturation $\left(\mathrm{SpO}_{2}\right)$ were recorded immediately after intubation. Animals were considered to be hypoxemic if the $\mathrm{SpO}_{2}$ values are $<95 \%$ and severely hypoxemic if the $\mathrm{SpO}_{2}<90 \%$.

A general health assessment including a full physical examination, weighing, biometric measurements, microchipping, sexing, full body radiographs and blood collection for in-house hematology and serum biochemistry profile were conducted on the civets. For the A-M group; the anesthesia was reversed with $0.25 \mathrm{mg} / \mathrm{kg}$ atipamezole (Atipam ${ }^{\circledR}$, Eurovet Animal Health B.V., Handelsweg, Netherlands). The reversal was injected into the quadriceps muscles. The civets were then placed in pet carriers for recovery. The time to removal of the endotracheal tubes, time to first sign of recovery and time to return to being ambulatory were all recorded. The endotracheal tubes were removed upon the return of the swallowing reflex in the civets. The first sign of recovery was recorded as the time taken for the civet to start responding to being handled. The return to an ambulatory state was recorded as the time taken for the civets to right themselves and start moving.

The quality of immobilization was subjectively evaluated based on the criteria described in Table 1 . 
Table 2. Induction and recovery times in minutes $(\mathrm{min})$ following the administration of alfaxalone-medetomidine or tiletamine-zolazepam in rescued common palm civet (Paradoxurus musangus)

\begin{tabular}{|c|c|c|c|c|c|}
\hline & \multicolumn{2}{|c|}{ A-M $M^{\text {a) }}$} & \multicolumn{2}{|c|}{$\mathrm{T}-\mathrm{Z}^{\mathrm{b})}$} & \multirow{2}{*}{ Distribution } \\
\hline & Mean \pm SD & Range & Mean \pm SD & Range & \\
\hline${ }^{1}$ Time to Initial Effects (min) & $2.99 \pm 1.10$ & $1.63-5.13$ & $2.67 \pm 1.66$ & $1.00-8.80$ & $\mathrm{NG}^{\mathrm{d})}$ \\
\hline${ }^{1}$ Time to Heavy Sedation (min) & $9.67 \pm 1.60$ & $6.32-13.80$ & $14.30 \pm 11.66$ & $2.80-36.03$ & NG \\
\hline${ }^{1}$ Time to Light Anethesia (min) & $14.24 \pm 4.27$ & $9.45-31.73$ & $20.64 \pm 13.6$ & $3.70-38.72$ & NG \\
\hline${ }^{1}$ Time to Intubation (min) & $19.17 \pm 5.14$ & $12.50-36.00$ & $25.17 \pm 14.07$ & $7.42-45.50$ & NG \\
\hline${ }^{2}$ Time to Extubation ${ }^{\mathrm{c})}(\mathrm{min})$ & $6.75 \pm 3.08$ & $2.00-15.00$ & $12.95 \pm 3.99$ & $7.00-20.00$ & NG \\
\hline${ }^{2}$ Time to Initial Sign of Recovery ${ }^{\mathrm{c}}$ (min) & $13.35 \pm 2.52$ & $10.00-19.00$ & $24.79 \pm 6.28$ & $15.00-40.00$ & NG \\
\hline${ }^{2}$ Time to Ambulatory ${ }^{\mathrm{c}}$ (min) & $25.10 \pm 5.41$ & $18.00-35.00$ & $46.89 \pm 12.48$ & $28.00-69.00$ & NG \\
\hline
\end{tabular}

a) Alfaxalone-medetomidine, b) Tiletamine-zolazepam, c) $P<0.05$, d) Non-Gaussian distribution. ${ }^{1}$ Time from anesthetics injection in both A-M and T-Z groups, ${ }^{2}$ Time from injection of reversal in A-M group, and time from cessation of isoflurane in T-Z group.

Table 3. The physiological parameters immediately after intubation in common palm civet (Paradoxurus musangus) with alfaxaolone-medetomdine and tiletamine-zolazepam

\begin{tabular}{|c|c|c|c|c|c|}
\hline & \multicolumn{2}{|c|}{$\mathrm{A}-\mathrm{M}^{\mathrm{a})}$} & \multicolumn{2}{|c|}{$\mathrm{T}-\mathrm{Z}^{\mathrm{b})}$} & \multirow{2}{*}{ Distribution } \\
\hline & Mean \pm SD & Range & Mean $\pm \mathrm{SD}$ & Range & \\
\hline Heart rate $\left.\left(\min ^{-1}\right)^{c}\right)$ & $115.3 \pm 28.4$ & $70.0-190.0$ & $167.5 \pm 40.8$ & $65.0-225.0$ & $\mathrm{G}^{\mathrm{d})}$ \\
\hline Respiratory $\left(\mathrm{min}^{-1}\right)$ & $29.7 \pm 10.9$ & $16.0-52.0$ & $26.4 \pm 8.5$ & $12.0-42.0$ & $\mathrm{G}$ \\
\hline $\left.\mathrm{SpO}_{2}(\%)^{\mathrm{c}}\right)$ & $90.1 \pm 3.8$ & $81.0-95.0$ & $94.2 \pm 3.1$ & $89.0-98.0$ & $\mathrm{NG}^{\mathrm{e})}$ \\
\hline Rectal temperature $\left.\left({ }^{\circ} \mathrm{C}\right)^{\mathrm{c}}\right)$ & $37.3 \pm 1.0$ & $34.7-38.5$ & $36.4 \pm 0.8$ & $34.6-38.3$ & $\mathrm{G}$ \\
\hline
\end{tabular}

a) Alfaxalone-medetomidine, b) Tiletamine-zolazepam, c) $P<0.05$, d) Gaussian distribution, e) Non-Gaussian distribution.

\section{Statistical analysis}

Data was analyzed using SPSS 17.0 (SPSS Inc., Chicago, IL, U.S.A.). The Kolmogorov-Smirnov test was used to assess data for normality. For data that was normally distributed, a parametric unpaired two-tailed $t$-test was used to assess difference between groups. If the data was not normally distributed, a non-parametric Mann-Whitney test was used. The level of significance was set at $P<0.05$.

\section{RESULTS}

No complications were noted during the induction and recovery of all the forty civets in both the A-M and T-Z groups. However, it was noted that all twenty civets (fifteen adults and five juveniles) that received T-Z, salivated during the anesthesia. Any saliva in the laryngeal region was removed with clean gauze swab prior to intubation for the T-Z group.

For the A-M group; nineteen civets (eleven adults and eight juveniles) but one civet were rated to have 'excellent' and did not require supplementary isoflurane to place on light plane of anesthesia or to maintain the anesthesia. The single juvenile civet was rated as 'moderate' in which it was sufficiently immobilized but requires supplementary isoflurane to enable intubation as it retain jaw tone and also to maintain the anesthesia.

For the T-Z group, seven civets (six adults and one juvenile) were rated as good as these civets were sufficiently immobilized and also able to be intubated with the drug combination. Isoflurane were required for these seven civets during the procedure the civets showed signs of recovery from anesthesia such as return of jaw tone and withdrawal reflex during the procedure. Eleven civets (seven adults and four juveniles) civets were rated as 'moderate' as they were sufficiently immobilized but retained jaw tone and swallowing reflex. These eleven civets required supplementary isoflurane to enable the animal to be intubated and also for the maintenance of anesthesia. Two adult civets were rated as 'poor' in which the civet was not sufficiently immobilized and required supplementary isoflurane for immobilization, intubation and maintenance of anesthesia.

There were no significant differences in the time of induction, time to recovery and all physiological parameters between the sexes and age groups for both drug combinations. Therefore, the data from males and females, as well as adults and juveniles, were pooled for each drug combination.

Induction and recovery times are summarized in Table 2. There were no significant differences in the time from anesthetic injection to induction and time to intubation between the A-M and T-Z groups. The time from the injection of reversal for the A-M group with 'excellent' rating except one juvenile civet from A-M group with 'moderate' rating which include time of cessation of isoflurane and the time of cessation of isoflurane for the all T-Z group to extubation, first response to recovery and ambulation were significantly $(P<0.05)$ longer in the T-Z group.

The respiratory rates, heart rates, temperature and $\mathrm{SpO}_{2}$ are summarized in Table 3. The rectal temperature in the A-M group was significantly $(P<0.05)$ higher than the T-Z group. The heart rate and $\mathrm{SpO}_{2}$ of the T-Z group were significantly $(P<0.05)$ higher than those of the A-M group. In the A-M group, twelve (nine adults and three juveniles) had hypoxemia and seven (five adults and two 
juveniles) had severe hypoxemia. The incident rate was $60 \%$ for hypoxemia and $35 \%$ for severe hypoxemia in the A-M group. A total of nine (seven adults and two juveniles) recorded incidence of hypoxemia and one juvenile civet suffered severe hypoxemia in the T-Z group. The incident rate was $45 \%$ for hypoxemia and $5 \%$ for severe hypoxemia in the T-Z group.

\section{DISCUSSION}

The present study revealed that both protocols can be used safely for the chemical restraint of civets for non-surgical procedures. However, there were significant differences in the level of immobilization and the recovery time between the two drug combinations. The A-M combination was rated to be the better anesthetic protocol compare to the T-Z combination as only one civet require supplementary isoflurane for intubation. This drug combination enabled the animals to be in a light to moderate anesthetic plane, which made intubation possible. For the T-Z combination only seven civets can be intubated without supplementary isoflurane. A total of thirteen civets still retain jaw tone and they required supplementary isoflurane to facilitate intubation. Furthermore, the T-Z combination at a dosage of $5 \mathrm{mg} / \mathrm{kg}$ was not sufficient to remove both pharyngeal and laryngeal reflex. Similar findings were reported in spotted hyenas [10]. Local anesthetic spray was required to remove pharyngeal and laryngeal reflexes to enable safe intubation [6].

The average rectal temperature of the T-Z group was found to be significantly lower than the A-M group, possibly due to the effect of zolazepam on the benzodiazepines receptors. Benzodiazepine drugs such as flurazepam and loprazepam have been reported to produce hypothermia due to full benzodiazepine receptor activation [11]. A similar hypothermic effect of the T-Z combination has been reported in the cynomogulus monkey [13].

The usage of $\alpha-2$ adrenoceptor agonist has been reported in several species to cause bradycardia and bradypnea [9, 12, 21]. Significant differences were observed between the heart rate of the A-M group and the T-Z group, likely due to the effects of medetomidine-an $\alpha-2$ adrenoceptor agonist-on the cardiovascular system. Heart rates may decrease to $50-75 \%$ in some individuals and was characterized by two or three sequential beats followed by a long sinus pause [12]. However, no significant reductions in the respiratory rates were noted in the A-M group. This has been reported in Bennett's wallabies using the alfaxalone and medetomidine combination [1]. The $\mathrm{SpO}_{2}$ of the A-M group was significantly lower in this study due to the depression of the cardiovascular and central respiratory canters by both alfaxalone and medetomidine [14, 15]. As hypoxemia can lead to anesthetic mortalities in wildlife, supplemental oxygen was provided to the civets via an endotracheal tube every time the $\mathrm{SpO}_{2}$ level fell below $90 \%$ in this study. Another possibility of the decreased $\mathrm{SpO}_{2}$ reading in the A-M group could be attributed to the vasoconstriction caused by $\alpha-2$ adrenoceptor agonist drugs resulting in a less accurate pulse oximetry reading [20].

Salivation was observed in all the civets administered with the T-Z combination. Similar findings have been noted in Arctic foxes and North American river otters [22, 24]. As endotracheal tubes were utilized across both groups, excess saliva had to be removed from the laryngopharyngeal area during intubation for individuals in the T-Z group. No signs of aspiration were observed in any of the civets from the T-Z group as a result of the salivation.

The anesthetic recoveries for all the civets in both groups were noted to be smooth with no adverse reactions to the drugs during the study. However, there was a significant difference observed between the recovery times of the A-M and the T-Z groups. This may be explained by the use of atipamezole to reverse the medetomidine component of the A-M combination. Administration of atipamezole at five times the medetomidine dose in this study resulted in rapid reversal without side effects such panting, trembling or excitement, just as reported in the European mink and pole cats [8]. None of the animals from the A-M combination required additional atipamezole for recovery. The T-Z combination could be partially reversed with flumazenil for the zolazepam component, and it has been recorded in cheetahs to significantly shorten the recovery period [24, 26]. Flumazenil could be used to decrease the recovery period of the T-Z combination, but this was not studied here. The ability of usage reversal agent in A-M group enables clinicians to quickly revive the animal for release or to recovery animal in emergency situation during the anesthesia [12].

This report indicated that while both the A-M and T-Z anesthetic drug combinations can be used, the A-M combination provided better anesthetic depth compared to the T-Z combination. However, higher incidence of bradycardia and hypoxemia were observed in the A-M group due to the presence of $\alpha-2$ agonist drug in the combination. The duration of the recovery time was also reduced significantly with the use of atipamezole for the A-M combination.

ACKNOWLEDGMENTS. We would like to acknowledge Professor Dr. Latiffah Hassan of the Universiti Putra Malaysia, for her invaluable help in the study. We would also like to thank the veterinary staff, especially Dr Xie Shangzhe, Dr Jessica Lee, Mr. Mulyadi Junid and Ms. Chen Yihui, from the Department of Conservation, Research and Veterinary Services, Wildlife Reserves Singapore, for their invaluable contribution during the sampling. Finally, we would like to thank the staff of the National Parks Board of Singapore for their help in the civets' rehabilitation.

\section{REFERENCES}

1. Bouts, T., Karunaratna, D., Berry, K., Dodds, J., Gasthuys, F., Routh, A. and Taylor, P. 2011. Evaluation of medetomidine-alfaxalone and medetomidine-ketamine in semi-free ranging Bennett's wallabies (Macropus rufogriseus). J. Zoo Wildl. Med. 42: 617-622. [Medline] [CrossRef]

2. Carder, G., Proctor, H., Schmidt-Burbach, J. and D'Cruze, N. 2016. The animal welfare implication of civet coffee tourism in Bali. Anim. Welf. 25: 199-205. [CrossRef]

3. D'Cruze, N., Toole, J., Mansell, K. and Schmidt-Burbach, J. 2014. What is the true cost of the world's most expensive coffee? Oryx 48: 169-171. 
[CrossRef]

4. Denver, M. 2003. Procyonidae and viverridae. pp. 516-523. In: Zoo and Wildlife Medicine. 5th ed. (Fowler, M.E. and Miller, R. E. eds.), Saunders, St. Louis.

5. Dodman, N. H. 1980. Complications of saffan anaesthesia in cats. Vet. Rec. 107: 481-483. [Medline] [CrossRef]

6. Ebner, J., Wehr, U., Busch, R., Erhardt, W. and Henke, J. 2007. A comparative clinical study of three different dosages of intramuscular midazolammedetomidine-ketamine immobilization in cats. J. Vet. Med. A Physiol. Pathol. Clin. Med. 54: 418-423. [Medline] [CrossRef]

7. Ferré, P. J., Pasloske, K., Whittem, T., Ranasinghe, M. G., Li, Q. and Lefebvre, H. P. 2006. Plasma pharmacokinetics of alfaxalone in dogs after an intravenous bolus of Alfaxan-CD RTU. Vet. Anaesth. Analg. 33: 229-236. [Medline] [CrossRef]

8. Fournier-Chambrillon, C., Chusseau, J. P., Dupuch, J., Maizeret, C. and Fournier, P. 2003. Immobilization of free-ranging European mink (Mustela lutreola) an polecat (Mustela putorius) with medetomidine-ketamine and reversal by atipamezole. J. Wildl. Dis. 39: 393-399. [Medline] [CrossRef]

9. Fournier, P., Fournier-Chambrillon, C. and Vié, J. C. 1998. Immobilization of wild kinkajous (Potos flavus) with medetomidine-ketamine and reversal by atipamezole. J. Zoo Wildl. Med. 29: 190-194. [Medline]

10. Jaarsveld, A. S. 1988. The use of Zoletil for the immobilization of spotted hyaenas. S. Afr. J. Wildl. Res 18: 65-66.

11. Jackson, H. C. and Nutt, D. J. 1990. Body temperature discriminates between full and partial benzodiazepine receptor agonists. Eur. J. Pharmacol. 185: 243-246. [Medline] [CrossRef]

12. Lamont, L. A. and Grimm, K. A. 2014. Clinical pharmacology. pp. 5-41. In: Zoo Animal and Wildlife Immobilization and Anesthesia, 2nd ed. (West, G., Heard, D. and Caulkett, N. eds.), Willey Blackwell, Ames.

13. López, K. R., Gibbs, P. H. and Reed, D. S. 2002. A comparison of body temperature changes due to the administration of ketamine-acepromazine and tiletamine-zolazepam anesthetics in cynomolgus macaques. Contemp. Top. Lab. Anim. Sci. 41: 47-50. [Medline]

14. Mathieu, A., Caulkett, N., Stent, P. M. and Schwantje, H. M. 2017. Capture of free-ranging mule deer (Odocoileus hemionus) with a combination of medetomidine azaperone and alfaxolone. J. Wildl. Dis. 53: 296-303. [Medline] [CrossRef]

15. Moll, X., Santos, L., García, F. and Andaluz, A. 2013. The effects on cardio-respiratory and acid-base variables of a constant rate infusion of alfaxalone-HPCD in sheep. Vet. J. 196: 209-212. [Medline] [CrossRef]

16. Moresco, A. and Larsen, R. S. 2014. Viverrids. pp. 619-625. In: Zoo Animal and Wildlife Immobilization and Anesthesia, 2nd ed. (West, G., Heard, D. and Caulkett, N. eds.), Willey Blackwell, Ames.

17. Murrell, J. 2009. Alfaxalone (Alfaxan ${ }^{\circledR}$ CD-RTU). Companion Anim. 14: 89-90. [CrossRef]

18. Navarrete-Calvo, R., Gómez-Villamandos, R. J., Morgaz, J., Manuel Domínguez, J., Fernández-Sarmiento, A., Muñoz-Rascón, P., López Villalba, I. and Del Mar Granados, M. 2014. Cardiorespiratory, anaesthetic and recovery effects of morphine combined with medetomidine and alfaxalone in rabbits. Vet. Rec. 174: 95. [Medline] [CrossRef]

19. Ng, P. K. L., Corlett, R. T. and Tan, H. T. W. 2011. Family: Viverridae. p. 256. In: An Encyclopedia of the Natural Environment and Sustainable Development. Singapore Biodiversity (Ng, P.K.L., Corlett, R.T. and Tan, H.T.W. eds.), Tien Wah Press, Singapore.

20. Ozeki, L. and Caulkett, N. 2014. Monitoring. pp. 43-51. In: Zoo Animal and Wildlife Immobilization and Anesthesia, 2nd ed. (West, G., Heard, D. and Caulkett, N. eds.), Wiley Blackwell, Ames.

21. Read, M. R. 2003. A review of alpha2 adrenoreceptor agonists and the development of hypoxemia in domestic and wild ruminants. J. Zoo Wildl. Med. 34: 134-138. [Medline] [CrossRef]

22. Samelius, G., Lariviere, S. and Alisauskas, R. T. 2003. Immobilization of arctic foxes with tiletamine hydrochloride and zolazepam hydrochloride $\left(\right.$ Zoletil $\left.^{\circledR}\right)$. Wildl. Soc. Bull. 31: 192-196.

23. Shepherd, C. R. 2012. Observation of small carnivores in Jakarta wildlife markets, Indonesia with notes on trade in Javan ferret badger Melogale orientalis and on the increasing demand for common palm civet Paradoxurus hermaphroditus for civet coffee production. Small Carniv. Conserv 47: $38-41$.

24. Spelman, L. H., Summer, P. W., Karesh, W. B. and Stoskopf, M. K. 1997. Tiletamine-zolazepam anesthesia in North American river otters (Lutra canadensis) and its partial antagonism with flumazenil. J. Zoo Wildl. Med. 28: 418-423. [Medline]

25. Villaverde-Morcillo, S., Benito, J., García-Sánchez, R., Martín-Jurado, O. and Gómez de Segura, I. A. 2014. Comparison of isoflurane and alfaxalone (Alfaxan) for the induction of anesthesia in flamingos (Phoenicopterus roseus) undergoing orthopedic surgery. J. Zoo Wildl. Med. 45: 361-366. [Medline] [CrossRef]

26. Walzer, C. and Huber, C. 2002. Partial antagonism of tiletamine-zolazepam anesthesia in cheetah. J. Wildl. Dis. 38: 468-472. [Medline] [CrossRef]

27. Whittem, T., Pasloske, K. S., Heit, M. C. and Ranasinghe, M. G. 2008. The pharmacokinetics and pharmacodynamics of alfaxalone in cats after single and multiple intravenous administration of Alfaxan at clinical and supraclinical doses. J. Vet. Pharmacol. Ther. 31: 571-579. [Medline] [CrossRef]

28. Xu, W. T. and Fung, T. K. 2010. Conservation and Research. Wildlife Times. Wildlife Reserves Singapore, Singapore. 